\title{
Progress in Recycling of Composites with Polycyanurate Matrix
}

\author{
Christian Dreyer, Dominik Söthje, Monika Bauer \\ Fraunhofer Research Institution for Polymeric Materials and Composites PYCO, Teltow, Germany \\ Email: christian.dreyer@pyco.fraunhofer.de
}

Received 26 February 2014; revised 26 March 2014; accepted 2 April 2014

Copyright (C) 2014 by authors and Scientific Research Publishing Inc.

This work is licensed under the Creative Commons Attribution International License (CC BY). http://creativecommons.org/licenses/by/4.0/

(c) (i) Open Access

\section{Abstract}

Thermoset based composites are used increasingly in industry for light weight applications, mainly for aircraft, windmills and for automobiles. Fiber reinforced thermoset polymers show a number of advantages over conventional materials, like metals, especially their better performance regarding their strength-to-weight ratio. However, composite recycling is a big issue, as there are almost no established recycling methods. The authors investigate the recyclability of polycyanurate homo- and copolymers with different recycling agents under different conditions. Also the influence of the recycling process on the most important reinforcement fibers, i.e. carbon-, glass-, aramid-, and natural-fiber is investigated. The authors find that: the recycling speed is not only dependent on the temperature, but also is significantly influenced by the particular recycling agents and the polycyanurate formulation. Hence, the stability against the recycling media can be adjusted over a broad range by adjusting the polymer composition. Furthermore, the authors find that the inorganic reinforcement fibers (carbon and glass) are almost unaffected by neither recycling agent at either temperature. Aramid-fibers degrade, depending on the particular recycling agent, from slightly up to extremely strong. This leaves one with the possibility to find a combination of matrix resin and recycling agent, which does not affect the aramid-fiber significantly. In the case of natural fibers, the dependence on the particular recycling media is very strong: some media do not affect the fiber significantly; others reduce the mechanical properties (tensile strength and elongation at break) significantly, and still others even improve both mechanical properties strongly. From the Recyclate, the authors synthesize and subsequently characterize a number of new polyurethane thermosets (foamed and solid samples) with different contents of recyclate, exhibiting $\mathrm{T}_{\mathrm{g}}$ in the range of $60^{\circ} \mathrm{C}$ to $128^{\circ} \mathrm{C}$.

\section{Keywords}

Polycyanurate, Composite Recycling, Thermoset, Cyanate Ester Resins, High Performance Polymers, Reinforcement Fiber, Carbon Fiber, Natural Fiber 


\section{Introduction}

Composites are combinations of two (or more) materials, where all individual components retain their separate identities. They are neither dissolved into each other, nor merged together. They also do not react chemically with each other (reactions of functional groups at the fiber-surface not taken into regard). The materials are mixed homogeneously, but they are still physically discrete and mechanically separable. Typically, the mechanical properties of the composites are superior to the properties of the individual components [1]. When mentioning composites in this paper, the authors refer to fiber reinforced polymers, in particular with a thermoset matrix.

Composites based on fiber reinforced polymers are used in a wide range of applications these days, in particular for light-weight structures. They are predominantly found in aviation (e.g. for the A380) but also in structures for wind turbines in the building sector and increasingly in the automotive field [2].

Light-weight construction with fiber-reinforced polymers has been known in the production of automobiles already since the 1950s [3]. Since the late 1980s, the average weight of a car has grown steadily, mainly caused by an increasing amount of active and passive safety systems and due to a rising demand for comfort [4]. Especially for electrically driven vehicles, the need to reduce weight is high, as a reduction of the weight of a middle-class E-car by $200 \mathrm{~kg}$ results in a range increase of 20 - $30 \mathrm{~km}$, which is quite significant when taking a typical range of around $150 \mathrm{~km}$ into regard [5]. In aircraft, the percentage of composites is increasing strongly, especially since the introduction of the A380 with more than 20 mass-\% of composites in the structure [6].

Composites show a number of advantages over conventional materials like metals: They have a higher performance per weight. Excellent strength- and stiffness-to weight-ratios are achievable. Using unidirectional laminates, direction-dependent strength and stiffness are possible and composites with polymer matrix typically show excellent resistance to corrosion and chemical attack. Of course, composites also show some disadvantages over the classical materials. Composites are usually more brittle than metals. They exhibit lower thermostability and lower flame resistance compared to most metals. Furthermore, they show a different impact behavior than metals, which can be deformed better plastically. The repair of the composites is also more complex than the repair of metals. For most metals, efficient recycling processes are established, which is not the case for composites (see Section 1.2).

\subsection{Polycyanurates}

From the second half of the 19th century, unsuccessful attempts to synthesize cyanates, the monomeric units of polycyanurates took place [7]. More than a hundred years later, in 1964, almost simultaneously in three workgroups, the main synthetic routes for the synthesis of cyanates were developed [8]-[10].

The polycyanurate ester resins obtained from (at least) difunctional Cyanate monomers were originally developed as matrix resins for laminated printed circuit boards, due to their excellent performance, especially regarding their high thermostability and low dielectric constant, their use extended to composites for avionics (air ducts, plenums etc.) rad domes and also for space applications [11].

In contrast to phenolic resins, which form water during their polycondensation reaction, cyanates react with themselves via cyclotrimerization (an additional hardener like in the case of epoxides is not required). The reaction scheme for the formation of a dense crosslinked polycyanurate network is shown in Figure 1.

Due to the high network density and the high content of aromatic rings, glass transition temperatures of up to $400^{\circ} \mathrm{C}$ are possible for polycyanurates [12]. In addition to a high thermal stability they also show a relatively high intrinsic flame retardancy [13] and good chemical stability [11]. Their good transparency, especially in the infrared wavelength region, makes them suitable for use in integrated optical devices [14]-[16].

Cyanates not only react with themselves, they react with various compounds, which gives one the possibility to develop polymers with adjusted property profiles for different applications. Furthermore, the various reaction routes give one the possibility to accelerate the reaction speed, making these polymers interesting for industries where fast curing is needed, like in the automotive industry [17]. Figure 2 gives an overview about the manifold reactions of cyanates.

Last but not least, the different resulting structural components, including the cyanurate-structure, which is responsible for the recyclabilities are described quantitatively for coreaction with phenolics and epoxides in [11], pp. 58-86. 


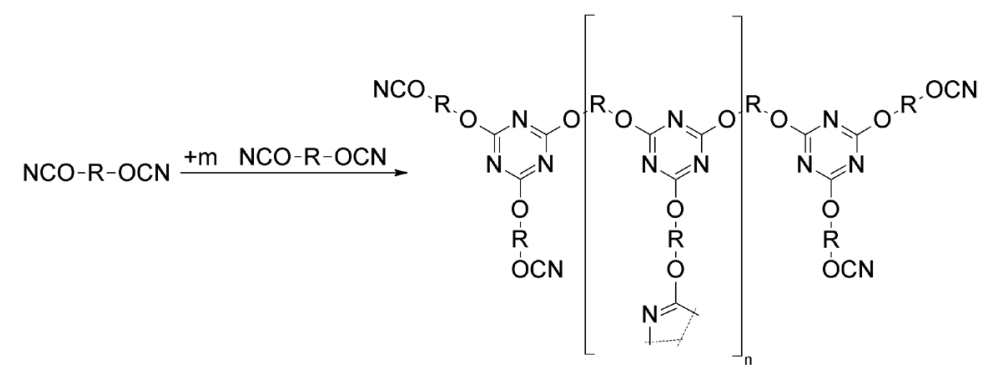

Figure 1. Polycyclotrimerization reaction of cyanates.

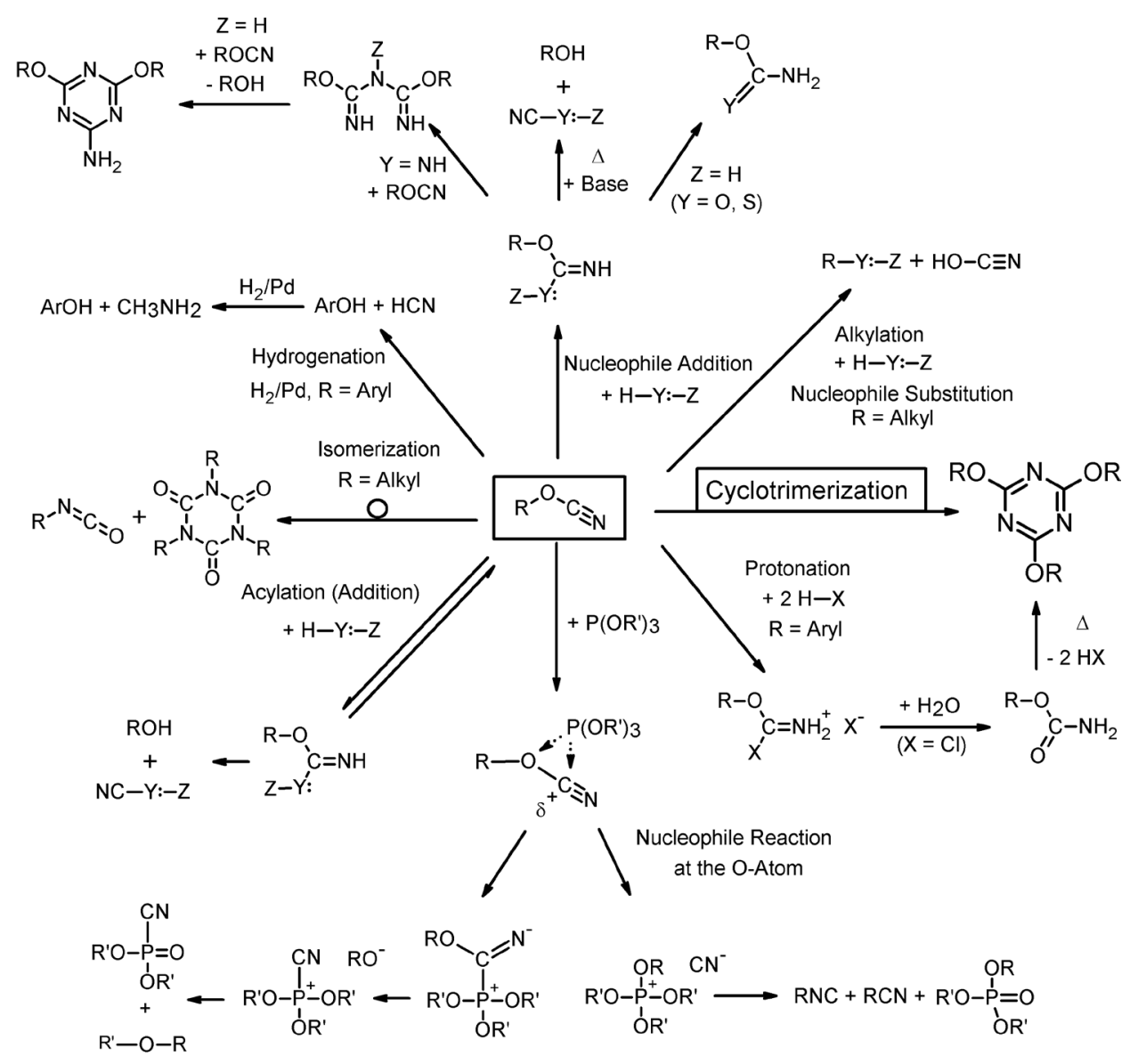

Figure 2. Reactions of cyanates with various compounds.

\subsection{State-of-the-Art Recycling of Composites}

Due to (expected) future governmental regulations, not only a high percentage of a car needs to be recycled at its end-of-life, also this will be demanded for aircraft in the future [18] [19]. With increasing use of composites the need for efficient recycling technologies will grow.

The major amount of composites has thermoset polymers as a matrix. As mentioned above, these polymers are in contrast to thermoplastic polymers [20]-[22] neither soluble nor meltable and therefore the main disposal route is landfilling, but also burning as well as milling and subsequent recovery as fillers (in small amounts). Not only the matrix polymer, but also the reinforcement fibers, which can be very price-intensive (e.g. in the case of carbon fibers), get lost by this procedure. Only a few publications are dealing with recycling and repair of epoxide resins, e.g. [23]-[25]. Furthermore pyrolysis, gasification, hydrolysis via subcritical resp. hypercritical water, and hydrogenation are under development for the recycling of composites [25]-[31]. 
Most of these common recycling methods do not reuse the matrix resin. A chemical recycling of epoxides is described in [24] [32]-[34]. But in this case, the recycling can only done for epoxides with a specific hardener, resulting in cured epoxides with a maximum $\mathrm{T}_{\mathrm{g}}$ of around $100^{\circ} \mathrm{C}$. The recycling is carried out under extremely mild conditions, having the big disadvantage of low media stability resulting therefrom.

Recycling of amine-cured epoxide thermosets by nitric acid leads to reusable glass fibers as well as reusable matrix material, nevertheless the recycling time is very long with approx. 400 hours [23].

\section{Recyclabilityof Polycyanurates}

Initial research on the recycling of polycyanurate thermosets was carried out by Bauer and Bauer already in the 1990s [35]. At that time, intense research was not done, because the need to recycle thermosets was relatively low. Lately, the interest in composite recycling is increasing, correlated to the extensive use in aircraft, windmills, trains and latterly in the automotive industry.

The recycling, i.e. chemical decomposition, of polycyanurates can be done under relatively mild conditions and within relatively short times.

The products of the cyanurate recycling are mainly triazine-containing structures and phenols. The particular recycling products depend of course on the original composition and the used recycling agent(s). Figure 3 depicts the principle reaction scheme of the chemical decomposition of a polycyanurate network. The recycling process can be done with a low amount of recycling agent and with low energy consumption, especially compared to pyrolysis [36].

The chemical nature of cyanates, to react with a variety of compounds, not only lets one adjust the propertyprofile of the resulting polymer, but also permits to change the recycling behavior. The incorporation of monofunctional cyanates and/or phenols results in an acceleration of the recycling process (under same conditions). Of course, the structure of the recycling agent as well as the temperature influences the recycling speed significantly. Detailed research on the recycling of cyanates is reported in section 3.2.1 of this paper.

\section{Experimental}

In this section, recycling experiments of polycyanurate homo- and copolymers, the investigations of the recycling processes' influence on different reinforcement fibers, and the synthesis of new PUR-thermosets are described.

\subsection{Materials}

\subsubsection{Recycling of Polycyanurates and Polycyanurate Copolymers}

As a model-thermoset for this research the commercially available Dicycanatobisphenol A (DCBA, B10), LONZA AG, Switzerland was selected. Sample plates with a thickness of approx. $6 \mathrm{~mm}$ were manufactured by curing the cyanate monomer in vertical aluminum molds under a defined temperature regime up to a final curing

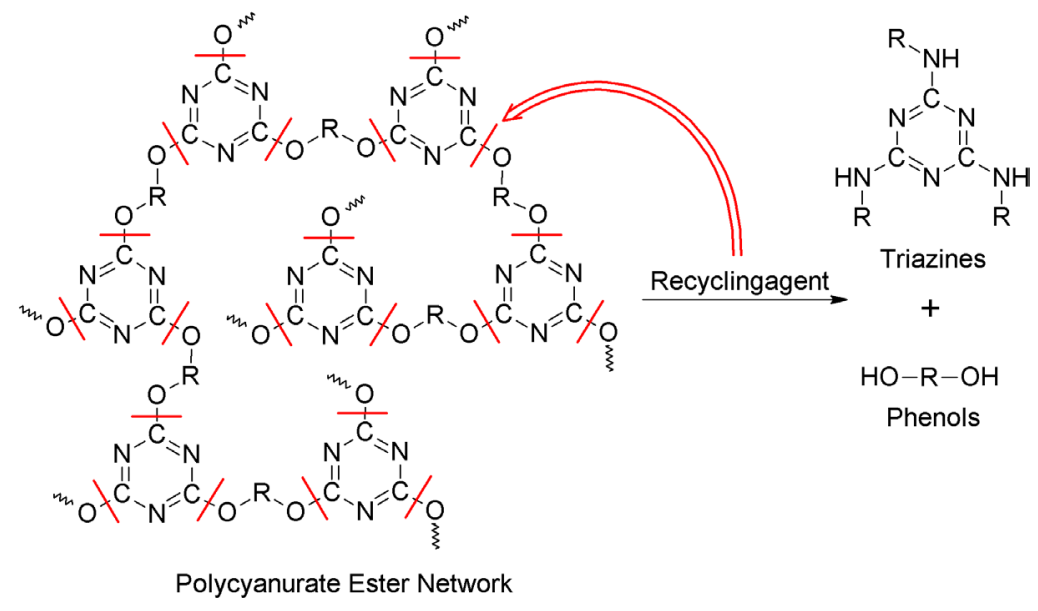

Figure 3. Chemical decomposition of polycyanurates. 
temperature of $250^{\circ} \mathrm{C}$, resulting in transparent brownish plates, showing a glass transition temperature $\left(T_{\mathrm{g}}\right)$ of about $287^{\circ} \mathrm{C}(\mathrm{DMA}, \tan \delta)$.

The synthesis of L10- and PT15-homopolymers and the different polycyanurate-copolymers were carried out analogously to the B10-synthesis. The curing regimes were modified for the particular formulations.

Twelve different recycling agents were used for decomposing the resin sample plates. In the following chapter they are continuously named from Agent A to Agent M.

\subsubsection{Effect of the Recycling Process on the Reinforcement Fibers}

For the research regarding the influence of different recycling agents on the reinforcement fibers four types of different fibers_for composite materials well known-were selected. As carbonfiber a $3 \mathrm{k}$ carbonfiber roving from SGL was chosen. Furthermore glass fiber rovings with approx. 680 dtex, Aramid fibers with approx. 1730 dtexand natural fiber yarns (flax), with approx. 530 dtex were selected.

\subsubsection{New Polyurethane Thermosets from Recycled Polycyanurates}

For the polyurethane-synthesis Glycerine (hydroxyl value: $1828 \mathrm{~g} \cdot \mathrm{kg}^{-1} \mathrm{KOH}$ ) and 1,4-Butanediol (hydroxyl value: $1240 \mathrm{~g} \cdot \mathrm{kg}^{-1} \mathrm{KOH}$ ) were selected as hydroxyl-compounds in addition to the OH-group containing recyclate.

As bio-based polyol castor oil (hydroxyl value: $160 \mathrm{~g} \cdot \mathrm{kg}^{-1} \mathrm{KOH}$ ) was chosen. As isocyanate components Desmodur N100 (1,6-hexamethylene-1,6-diisocyanate based aliphatic polyisocyanate, HDI-Biuret, NCO-group content of $22.0 \% \pm 0.3 \%$ ) and Desmodur N3300 (hexamethylene-1,6-diisocyanate based trimer, HDI-Trimer, NCO-group content of 21.8\% $\pm 0.3 \%$ ) both obtained from Bayer MaterialScience and ISO 134/3 (polymeric, aromatic diphenylmethanediisocyanate, P-MDI, NCO-group content of 24.6\%) obtained from BASF, were selected. As a blowing agent water was added to the corresponding formulations. The above mentioned chemicals for the synthesis of the new polyurethane thermosets are depicted in Table 1.

\subsection{Synthesis and Recycling Procedure}

\subsubsection{Decomposition of Polycyanurates and Polycyanurate Copolymers}

The recycling process was carried out in a $50 \mathrm{ml}$ flask equipped with a condenser for temperatures $>60^{\circ} \mathrm{C}$. For experiments at lower temperatures, closed Duran ${ }^{\circledR}$ bottles were used. Details regarding recycling and work up can be found in reference [37].

\subsubsection{Effect of the Decomposition Process on the Reinforcement Fibers}

The media stability experiments on the reinforcement fibers were carried out in $50 \mathrm{ml}$ flasks equipped with a condenser.

\subsubsection{Synthesis of Polyurethanes from Recyclate}

The recycling process was carried out in a $500 \mathrm{ml}$ flask equipped with magnetic stirrer and condenser. Agent Hwas used in excess as recycling agent at the boiling point $\left(172^{\circ} \mathrm{C}\right)$. The recycling time was $16 \mathrm{~h}$ and $2 \mathrm{~h}$ respectively. The excess of Agent $\mathrm{H}$ was removed via distillation. The dark brown highly viscous residue was used without further purification. Details regarding recycling and work up can be found in reference [37].

The different formulations were all targeted to obtain a 90\% conversion of the OH-groups. Formulations P1 P3 were synthesized using recyclate 1, P4 - P6 were synthesized using recyclate 2. 1,4-Butanediol, respectively castor oil acted as a solvent and a chain extender. Glycerin was used as a crosslinker in formulations P1-P3 and P6. Table 2 gives an overview about the polyurethane-formulations used.

The components were mixed in a Speedmixer ${ }^{\mathrm{TM}}$ from the company Hauschild, poured into molds, precured for $24 \mathrm{~h}$ at RT, followed by a curing step for $1 \mathrm{~h}$ at $100^{\circ} \mathrm{C}$. To obtain a complete conversion, a postcure for $1 \mathrm{~h}$ at $150^{\circ} \mathrm{C}$ was done.

For the formulations P1-P3 foams with different densities were obtained. P4-P6 produced massive samples. Some of the samples are shown in Figure 4 (left: massive PUR, right: foams from formulations P1-P3).

\subsection{Characterization Methods}

\subsubsection{Determination of Hydroxyl-Values}

For the recyclate after $16 \mathrm{~h}$ (recyclate 1) a hydroxyl-value of $486 \mathrm{~g} \cdot \mathrm{kg}^{-1} \mathrm{KOH}$ was estimated (ideal network 
Table 1. Chemicals for synthesis of new thermosets.

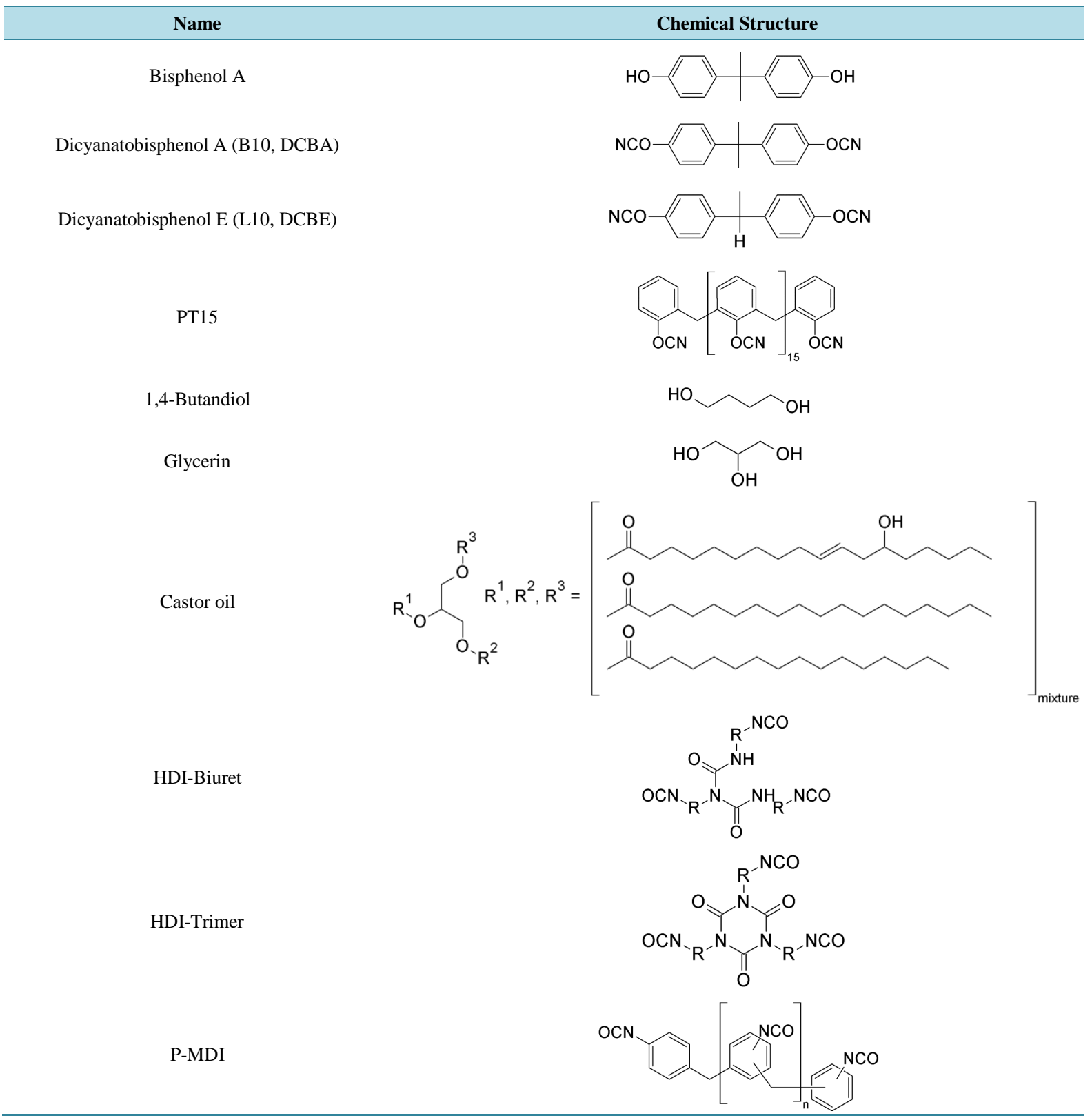

Table 2. Polyurethane formulations.

\begin{tabular}{|c|c|c|c|c|c|c|}
\hline Formulation & $\begin{array}{c}\text { KOH-value } \\
\left.\text { [g· } \mathbf{k g}^{-1} \mathrm{KOH}\right]\end{array}$ & Chain extender & Isocyanate & Cross-linking agent & Blowing agent & $\begin{array}{c}\omega_{\text {Recyclate }} \\
\text { [wt-\%] }\end{array}$ \\
\hline $\mathrm{P} 1$ & $486^{*}$ & 1,4-Butandiol & HDI-Biuret & Glycerin & Water & 13.2 \\
\hline $\mathrm{P} 2$ & $486^{*}$ & 1,4-Butandiol & P-MDI & Glycerin & Water & 14.3 \\
\hline P3 & $486^{*}$ & Castor oil & HDI-Biuret & Glycerin & Water & 22.4 \\
\hline $\mathrm{P} 4$ & $653^{* *}$ & 1,4-Butandiol & HDI-Trimer & - & - & 10.0 \\
\hline P5 & $653^{* *}$ & 1,4-Butandiol & HDI-Trimer & - & - & 20.0 \\
\hline P6 & $653^{* *}$ & 1,4-Butandiol & HDI-Trimer & Glycerin & - & 20.0 \\
\hline
\end{tabular}

*Estimated hydroxyl-value; ${ }^{* *}$ Hydroxyl values determined in accordance with DIN 53240. 


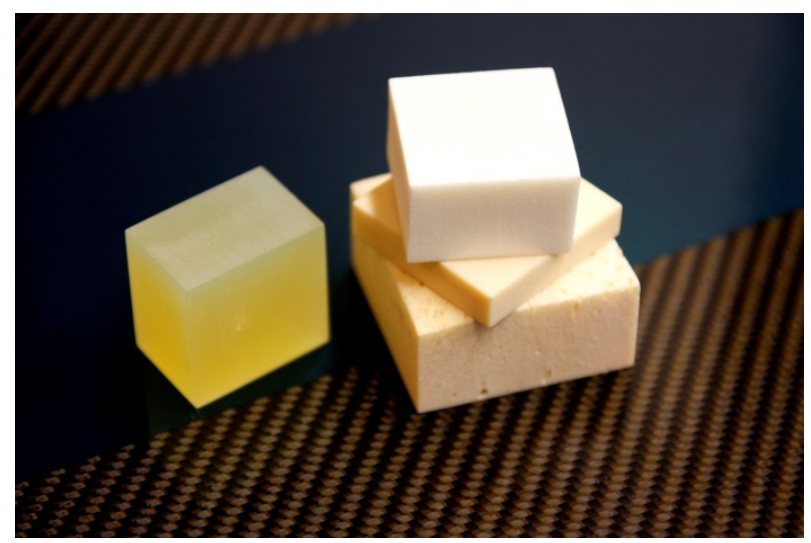

Figure 4. Massive (left) and foam (right) PUR-samples from polyurethane recyclate on a carbon-fiber reinforced polycyanurate-laminate.

formation and ideal decomposition assumed). The hydroxyl-value of $653 \mathrm{~g} \cdot \mathrm{kg}^{-1} \mathrm{KOH}$ for the recyclate after $2 \mathrm{~h}$ (recyclate 2) was determined in accordance with DIN 53240 [38].

\subsubsection{SEC-Chromatography}

The completeness of the decomposition was determined via size exclusion chromatography (SEC), using Tetrahydrofuran (THF) as an eluent at a flow rate of $1 \mathrm{ml} \cdot \mathrm{min}^{-1}$.

\subsubsection{DSC-Analysis}

The melting behavior of the crude recyclate was determined via Dynamic Scanning Calorimetry (DSC) (10 $\mathrm{K} \cdot \mathrm{min}^{-1}, 25^{\circ} \mathrm{C}-200^{\circ} \mathrm{C}$ ), exhibiting a melting range of $80^{\circ} \mathrm{C}-100^{\circ} \mathrm{C}$.

The complete curing of the new polymers was determined by DSC from $25^{\circ} \mathrm{C}$ to $150^{\circ} \mathrm{C}$ with a heating rate of $10 \mathrm{~K} \cdot \mathrm{min}^{-1}$.

DSC-measurements were performed on a Mettler-Toledo DSC 821.

\subsubsection{DMA-Measurements}

Dynamic Mechanical Analysis (DMA) was performed in torsion with an ARES Rheometer from TA Instruments. Storage (G') and loss (G”) modulus as well as $\tan \delta$ were determined as a function of temperature. The samples were heated from $30^{\circ} \mathrm{C}$ to $150^{\circ} \mathrm{C}$ with a heating rate of $4 \mathrm{~K} \cdot \mathrm{min}^{-1}$ at a torsion frequency of $1 \mathrm{~Hz}$.

\subsubsection{Mechanical Measurements}

To determine the mechanical properties of the treated and untreated fibers a tensile strength measurement machine from Instron was used. For each experiment regime 5 to 10 tensile tests were carried out.

\section{Results and Discussion}

In this section, the results of the experimental work on the recycling of polycyanurate homo- and copolymers, using different recycling agents under different temperatures, will be discussed. The second part covers the investigations concerning the influence of the recycling process on different reinforcement fibers. The third and last part gives an overview about the synthesized new PUR-thermosets.

\subsection{Recycling of Polycyanurates and Polycyanurate Copolymers}

Multiple factors influence the recyclability of polycyanurate ester resins and their copolymers: The recyclability of different fully cured polycyanuarate homopolymers under same conditions is significantly different, as shown in Figure 5.

Here the mass loss of the polycyanurate sample plates (due to the chemical decomposition in the recycling agent) is plotted against the recycling time. It can be seen clearly, that the reaction rate from B10 via L10 to PT 


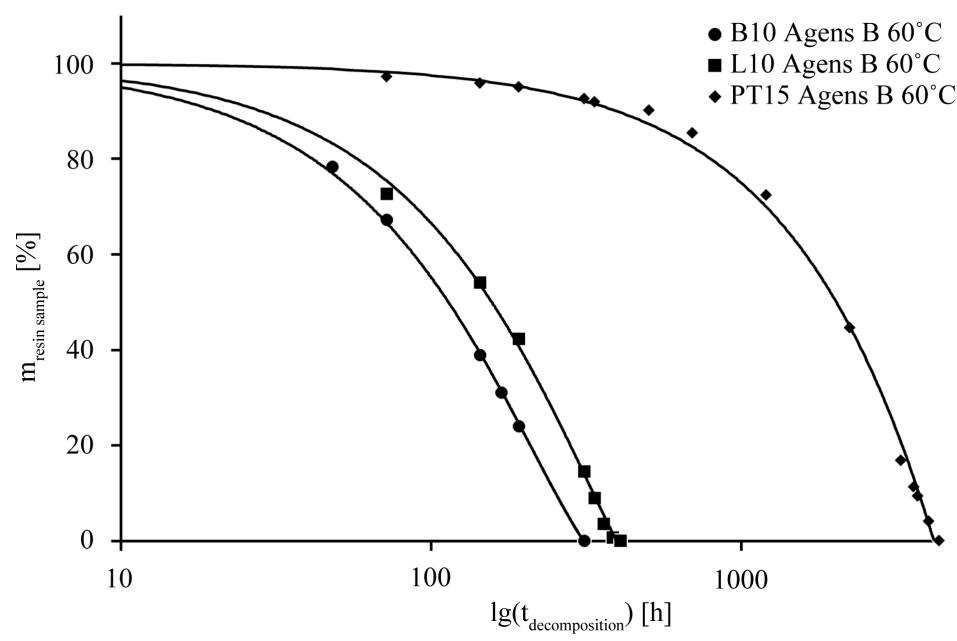

Figure 5. Recycling behavior of cured B10, L10 and PT15 (Table 1) in recycling agent $\mathrm{B}$ at $60^{\circ} \mathrm{C}($ accuracy $\pm 12 \mathrm{~h})$.

15 is decreasing. A complete decomposition of B10 is reached after about $300 \mathrm{~h}$, compared to $400 \mathrm{~h}$ for L10 and more than $4000 \mathrm{~h}$ for PT15. The extreme difference in recycling time between the polymers obtained from the two difunctional cyanate-monomers B10 and L10 and the polyfunctional PT15 is not really surprising, because to release the polyphenol-units from the PT15-network a significant higher number of cyanurate bonds need to be decomposed, than to release the bisphenol-units in case of B10 and L10.

The influence of different recycling agents on the recycling behavior is shown in Figure 6. It can be seen, that the recycling times for the same Polycyanurate homopolymer vary between $48 \mathrm{~h}$ and $816 \mathrm{~h}$ (for a complete decomposition, i.e. complete dissolution of the polycyanurate in the recycling agent).

Figure 7 shows impressively the big differences in the recycling times beginning from approx. $48 \mathrm{~h}$ up to approx. $816 \mathrm{~h}$ for cured B10 samples depending on the particular recycling agent.

An increase of the reaction temperature results also for the chemical recycling of the polycyanurates-in an increase of the decomposition rate-as it is usual for a typical organic reaction. Figure 8 shows the decomposition times of the three cured polycyanurates B10, L10 and PT15 in recycling agent B at $60^{\circ} \mathrm{C}$ and under refluxing conditions. One can see the dramatic reduction of the recycling times by a factor of at least 10. It is remarkable, that the decomposition of $\mathrm{B} 10$ at $60^{\circ} \mathrm{C}$ with $312 \mathrm{~h}$ is faster than that of $\mathrm{L} 10$ (408 h). Under refluxing conditions this effect is reversed so that L10 (18 h) is faster decomposed than B10 (36 h).

Under ambient pressure, the highest temperature which can be applied is the boiling temperature of the recycling agent. It can be seen in Figure 9, that the recycling times can be reduced down to approx. $1 \mathrm{~h}$ when doing the recycling under reflux. The columns are correlated to the recycling times in hours, the solid squares are correlated to the boiling point of the respective agents, which are identical with the recycling temperatures (with agent $\mathrm{L}$ and $\mathrm{M}$ as exceptions, where a recycling temperature of $195^{\circ} \mathrm{C}$ was used due to their high boiling points). Figure 7 and Figure 9 cannot be compared directly, as the mass-ratio of polycyanurate to recycling agent is 1:10 for Figure 7 and 1:4 for Figure 9, resulting in a higher recycling time for agent $C$ at boiling point (138h) than at $60^{\circ} \mathrm{C}(72 \mathrm{~h})$. A correlation between the boiling point resp. the recycling temperature and the recycling speed cannot be seen directly, as the efficiencies of the particular agents are obviously strongly different as can be seen in Figure 7. When comparing similar chemical structures (as for agents A, B, and C, which differ only in their chain length) the recycling efficiency seems to be correlated with the recycling temperature (Figure 9).

A further attempt to investigate the recycling processes was done by using 3-Aminophenol dissolved in an inert solvent as recycling agent (mass-ratio 20:80). It can be seen in Figure 10 that the 3-Aminophenol in n-Butanol, having a boiling-point of $118^{\circ} \mathrm{C}$ decomposes approx. 6 times faster compared to 3-Aminophenol in THF (boiling point $66^{\circ} \mathrm{C}$ ) or in Ethanol (boiling point $78^{\circ} \mathrm{C}$ ). Between the two lower boiling solvents there is no significant difference observable; the corresponding trendlines are almost identical.

As already mentioned in section 1.1, the property profile of polycyanuarate ester resins can be adjusted over a broad range due to the various reactions which cyanates can undergo. The recyclability of the cyanates of course also depends on the particular cyanate, as explained in Figure 5. Due to the possibility to copolymerize the cya- 


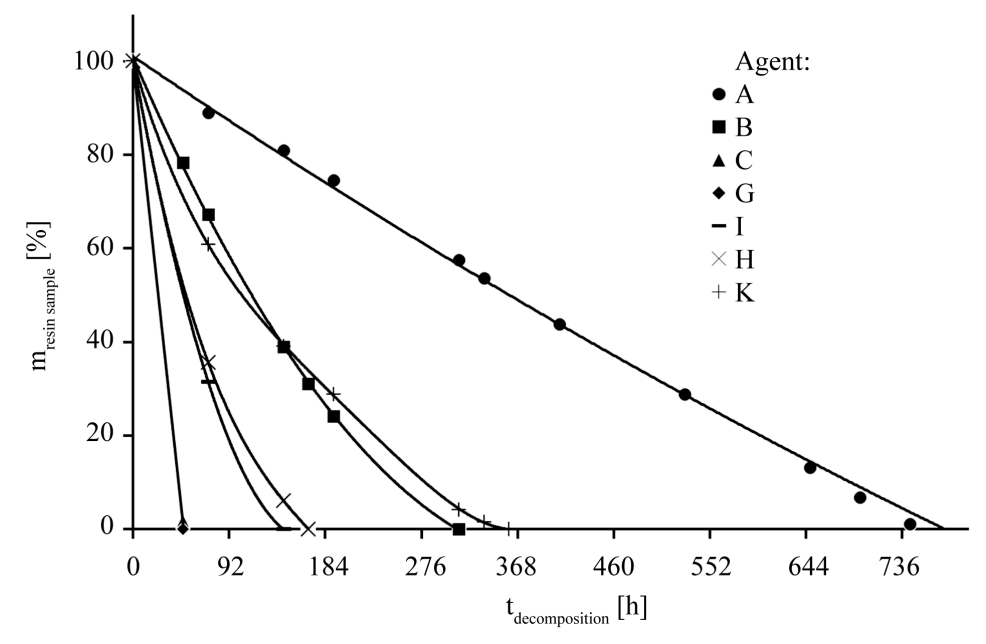

Figure 6. Recycling behavior of cured B10 sample plates in different recycling agents at $60^{\circ} \mathrm{C}$ (mass ratio B10:agent $=1: 10$ ) (accuracy $\pm 12 \mathrm{~h}$ ).

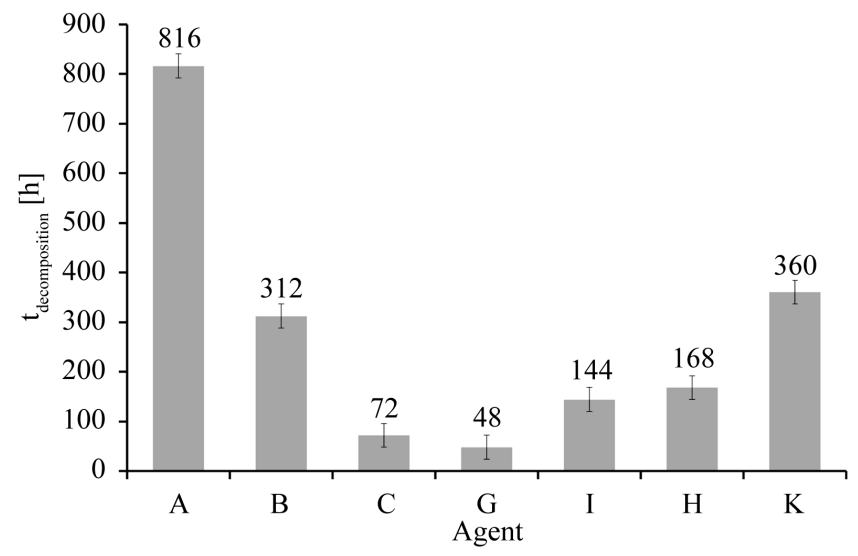

Figure 7. Recycling times of cured B10-Polycyanurate samples in seven different recycling agents at $60^{\circ} \mathrm{C}$ (mass ratio $\mathrm{B} 10$ :agent $=$ $1: 10)$.

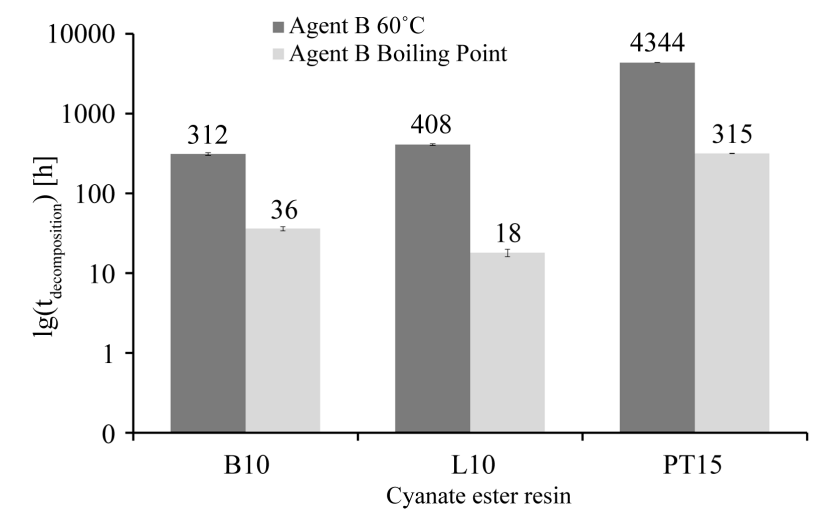

Figure 8. Recycling times of cured Polycyanurate samples at $60^{\circ} \mathrm{C}$ and under refluxing conditions in recycling agent $\mathrm{B}$.

nates with different coreactants, the recyclability of a cyanate can either be increased or decreased, depending on the nature of the coreactant(s). Figure 11 shows the decomposition curves of L10 copolymerized with two dif- 


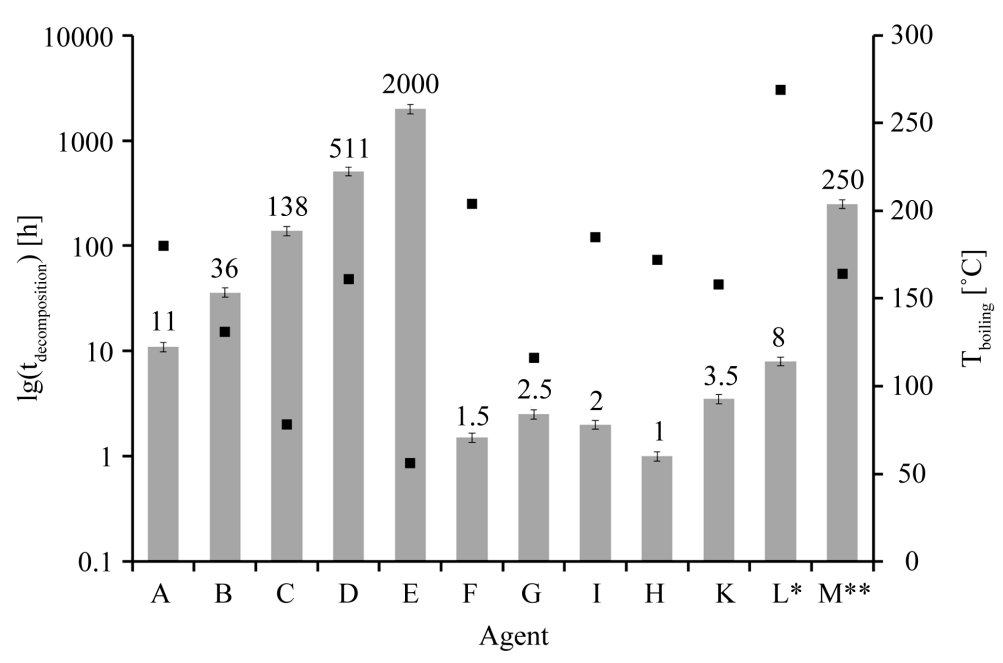

Figure 9. Recycling times of cured B10-Polycyanurate samples in 12 different recycling agents at their respective boiling point (mass ratio B10:agent = 1:4; columns heights are correlated to the recycling time, solid squares to the boiling point; ${ }^{*} T_{\text {decompositon }}=195^{\circ} \mathrm{C} ;{ }^{* * *} T_{\text {decompositon }}=195^{\circ} \mathrm{C}$ and $T_{\text {boilina }}=164^{\circ} \mathrm{C}$ at15 mbar).

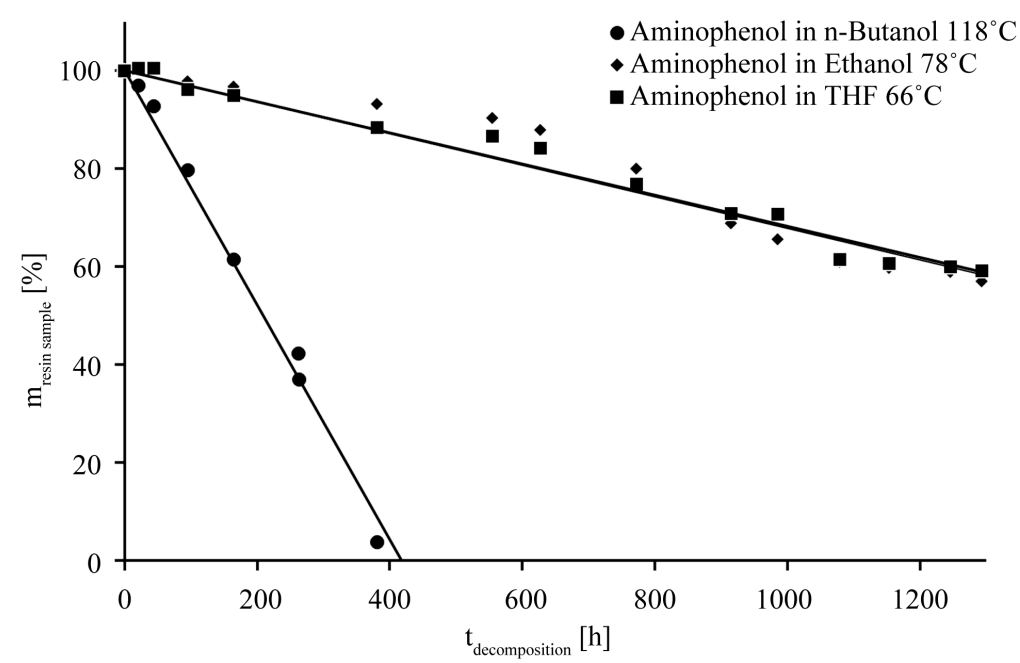

Figure 10. Recycling behavior of cured B10-Polycyanurate samples in solutions of 3-Aminophenol in n-Butanol •, Ethanol $\bullet$, and THF $\mathbf{~ ( m a s s - r a t i o ~ 2 0 : 8 0 ) ~}$ (accuracy \pm 12 h).

ferent comonomers $\mathrm{A}$ and $\mathrm{B}$ in different mass ratios in agent $\mathrm{H}$ at $40^{\circ} \mathrm{C}$. The decomposition curves of unmodified (cured) L10 and B10 are also given for comparison. The copolymerization of L10 with Comonomer A results in a reduction of the network density, causing a faster decomposition in the used recycling agent $\mathrm{H}$. The copolymerization of L10 with Comonomer B forms network links, which cannot be decomposed by the recycling agent, which can be clearly seen in Figure 11, as the recycling time increases with the mass-content of Comonomer B. The copolymer with a mass ratio of 50:50 is not recyclable within 7000 hours under these conditions.

The influence of the temperature on the reaction rate is also given for the cyanate copolymers. Figure 12 shows the decomposition curves of L10, L10 + 10 wt-\% Comonomer B and L10 + 20 wt- $\%$ Comonomer A in recycling agent $\mathrm{H}$, at $20^{\circ} \mathrm{C}$ and $40^{\circ} \mathrm{C}$ for each formulation. The decomposition speed is increasing for each polymerformulation, when raising the temperature from $20^{\circ} \mathrm{C}$ to $40^{\circ} \mathrm{C}$. Interestingly the reaction rate is increased by a factor of 6 to 7 irrespective of the particular formulation. 


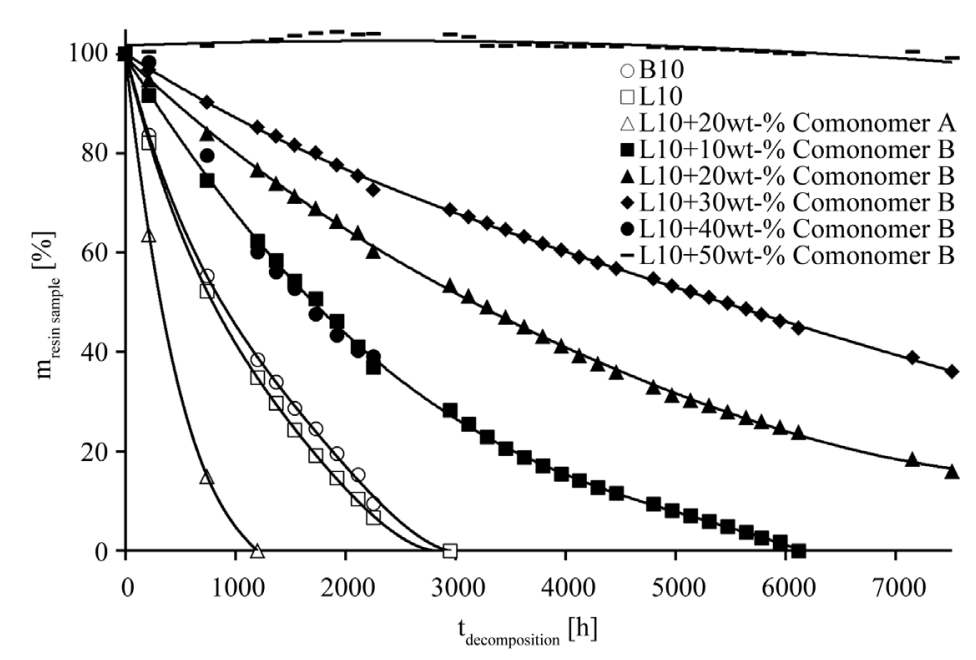

Figure 11. Recycling behavior of cured L10-copolymersamples with different coreactants and in different mass-ratios in recycling agent $\mathrm{H}$ at $40^{\circ} \mathrm{C}$ (neat cured L10 and B10 are depicted for comparison, accuracy $\pm 12 \mathrm{~h}$ ).

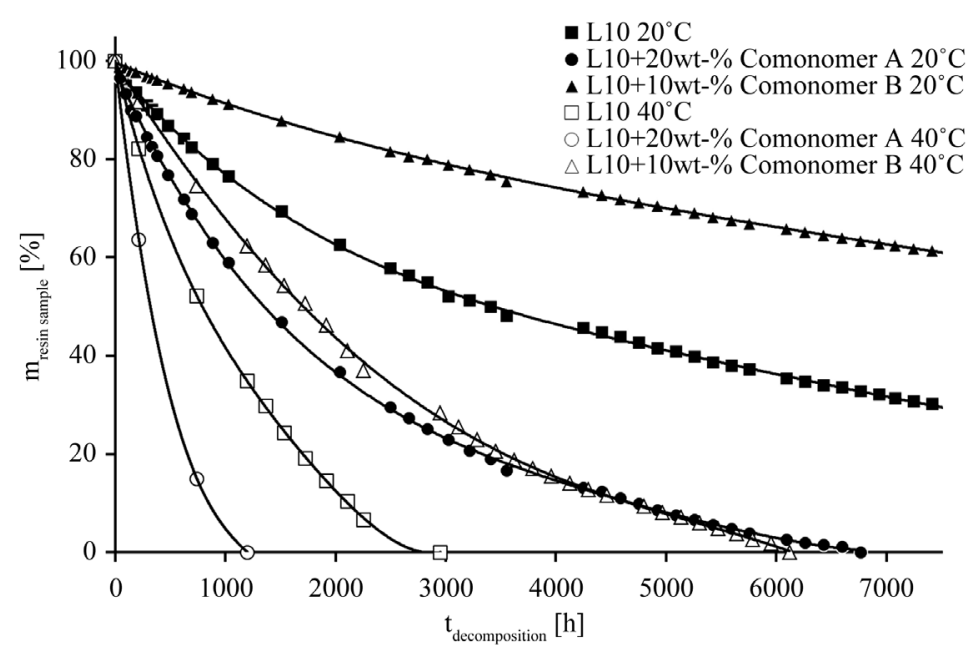

Figure 12. Recycling behavior of cured L10-Homo-and-Copolymer samples in recycling agent $\mathrm{H}$ at $20^{\circ} \mathrm{C}$ and $40^{\circ} \mathrm{C}$ (accuracy $\pm 12 \mathrm{~h}$ ).

\subsection{Effect of the Recycling Process on the Reinforcement Fibers}

Another major issue for the recycling is the influence of the recycling agents on the reinforcement fibers. The authors investigated the influence of seven different recycling agents on carbon-, glass-, aramid-, and natural fibers at $60^{\circ} \mathrm{C}$. The respective recycling times were selected in such a way, that the model-polycyanurate matrix, cured B10, completely decomposes under these conditions. The results of the tensile tests of the treated fibers can be seen in Figure 13. The respective recycling time is marked with black squares. Due to the high differences in tensile strengths of the different fibers, the values for tensile strength and elongation at break were normalized to $100 \%$ for the untreated fibers. Each column represents the mean value of 5 to 10 single measurements. The normalized tensile strength values are shown in Figure 13(a). One can see, that carbon- and glassfibers are not affected significantly by the recycling process, independent from the respective recycling agent. More evident is the influence on the aramid-fiber: Depending on the recycling agent the tensile strength is reduced down to approx. 30\% (agent H). Using agents B and C, the fiber retains approx. $90 \%$ of its initial tensile strength. Interestingly, there is no direct correlation between the recycling time and the reduction of the tensile strength for aramid, e.g. treatment with agent I for $144 \mathrm{~h}$ results in a remaining tensile strength of less than $30 \%$, while the aramid-fiber retains approx. $80 \%$ of its tensile strength after $816 \mathrm{~h}$ in agent $\mathrm{A}$. 


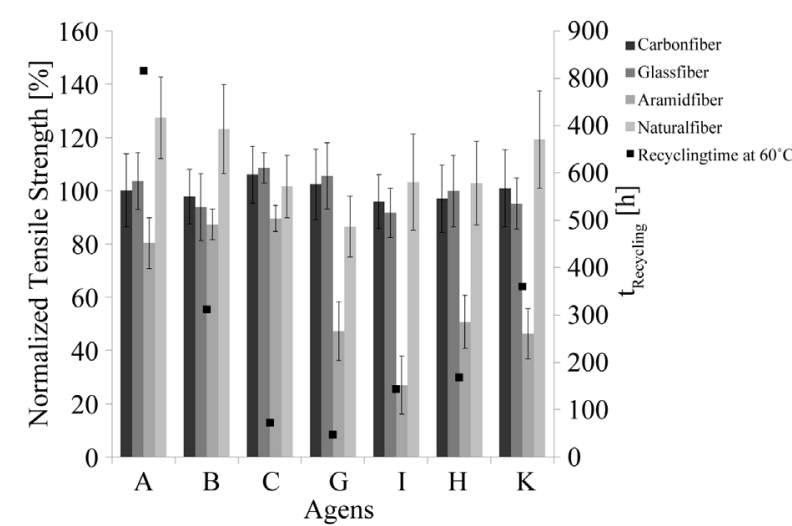

(a)

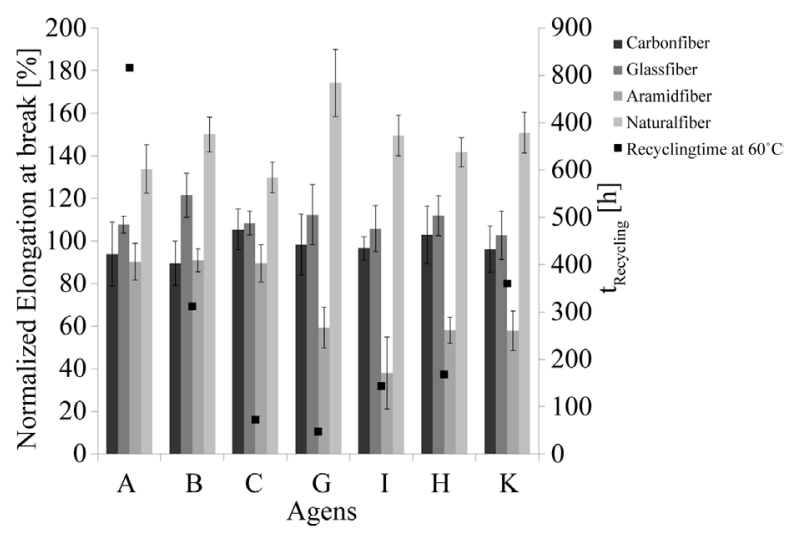

(b)

Figure 13. Normalized tensile strengths (a) and elongations at break (b) of reinforcement fibers after treatment in seven different recycling agents at $60^{\circ} \mathrm{C}$ (Initial values $=100 \%$ ). The recycling times (represented by $\mathbf{\square}$ ) are identical with the times needed to decompose the polycyanurate matrix (in this example cured B10).

The natural-fibers are negatively influenced only in case of agent A (approx. 90\% remaining tensile strength). It is remarkable, that for agents A and B the tensile strength increases to values $>120 \%$, which indicates a chemical modification by the recycling agent.

The values for the normalized elongation at break are affected relatively little for carbon- and glass-fibers (Figure 13(b)). In case of the glass-fibers in principle a slight increase of the elongation at break can be observed; nevertheless the low absolute values of glass must be taken into account (a elongation from 1.5\% up to $1.8 \%$ is not necessarily significant). Remarkable is the increase of the natural fiber values (between approx. $130 \%$ to approx. 170\%). An increase of the elongation at break values for all agents with only one exception (agent G) was observed, meaning, that the modification of natural fibers causes (with exception of $G$ ) an improvement of the mechanical properties tensile strength and elongation at break. Also remarkable is the increase of the elongation at break for the natural fiber in agent $G$ to approx. $170 \%$ by only a slight decrease of the tensile strength down to approx. $80 \%$ of the initial value.

The normalized elongations at break of the aramid fibers after the recycling process are directly correlated to the tensile strength values. To be more precise: The agents A, B, and C reduce the mechanical values only marginally, thus affecting the aramid not significantly (reduction of approx. 10\%), whereas the other agents yield a reduction of approx. $50 \%$, for agent I of even more than $60 \%$.

The outcome of more detailed examinations regarding the influence of agents $\mathrm{A}, \mathrm{G}$ and $\mathrm{H}$ for $1 \mathrm{~h}$ at $80^{\circ} \mathrm{C}$, $100^{\circ} \mathrm{C}$, and at the chemicals' boiling points on the fibers is displayed in Figure 14.

The carbon-fibers are essentially affected by neither agent nor temperature. There is no significant change in the mechanical values, besides a slight increase of the tensile strength under the regime at the boiling point of agent $\mathrm{H}$. The glass-fibers, too, are relatively unaffected; a trend to a slight decrease (less than $10 \%$ ) of the tensile strength with agent $A$ and a slight increase of the tensile strength with agents $G$ and $H$ is to be visible. The values of elongation at break seem to increase slightly (10\% - 20\%) compared to the initial point.

The effect on aramid-fibers is strongly depending on the particular agent. Agent A reduces the mechanical values only marginally, whereas $\mathrm{G}$ and $\mathrm{H}$ reduce both, tensile strength and elongation at break, especially at the boiling point extremely.

Very interesting are the effects on the natural-fibers: Here we get for almost all scenarios an increase of the tensile strength up to approx. 25\%; furthermore the elongation at break shows for $\mathrm{A}$ and $\mathrm{H}$ only a low increase, but for agent $\mathrm{G}$ the elongation at break is $150 \%$ - 200\% higher than the initial values.

Because only the aramid-fibers were affected negatively under the above mentioned conditions, further experiments were carried out: A comparative graph of carbon-, glass-, and natural-fibers treated with agents A, G and $\mathrm{H}$ for 24 hours at boiling point is given in Figure 15.

One can see that the different agents have only a minor effect on the carbon- and glass-fibers (approx. $\pm 10 \%$ to the initial values for agent $A$ ). The influence on natural-fibers is strong: A tensile strength reduction of approx. $10 \%$ (agent $\mathrm{H}$ ) resp. approx. 30\% (agent $\mathrm{A}$ ) can be found, but most interesting is the increase of $+310 \%$ for the 

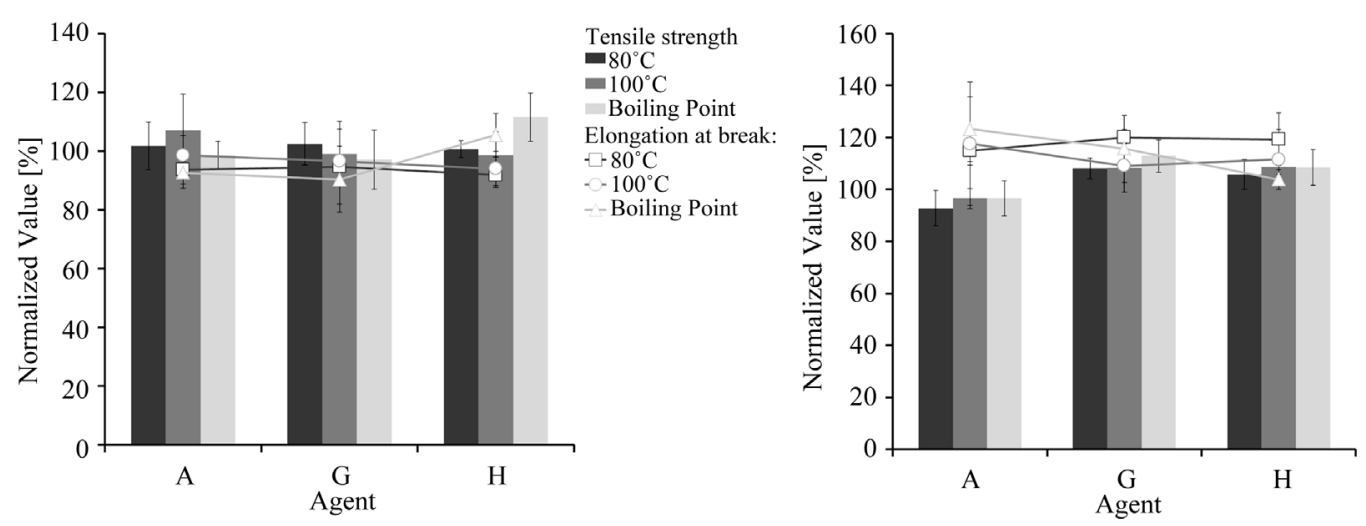

(b)

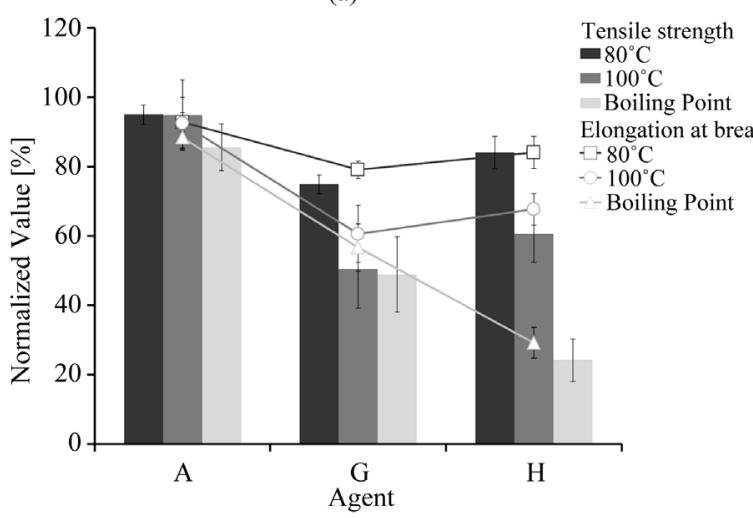

(c)

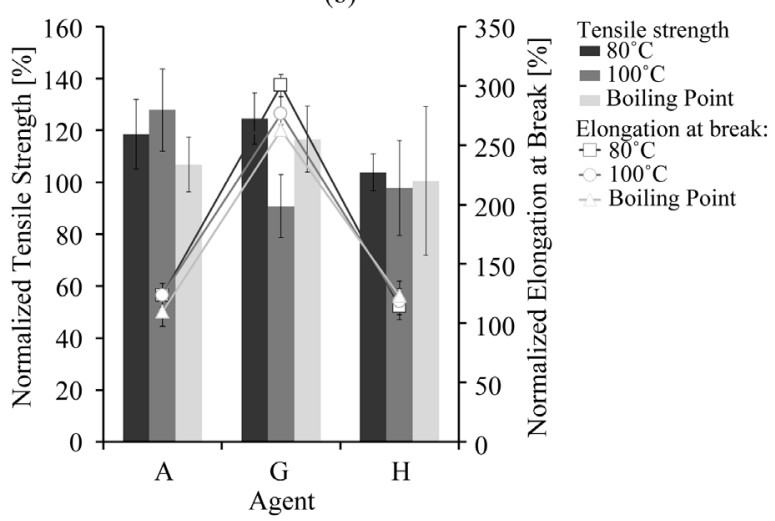

(d)

Figure 14. Influence of the agents $\mathrm{A}, \mathrm{G}$ and $\mathrm{H}$ on the four different fiber-species. Treatment for $1 \mathrm{~h}$ at $80^{\circ} \mathrm{C}, 100^{\circ} \mathrm{C}$, and the particular boiling point. The columns correspond to the tensile strength values and the points to the elongation at break values after treatment; initial values are normalized to $100 \%$.

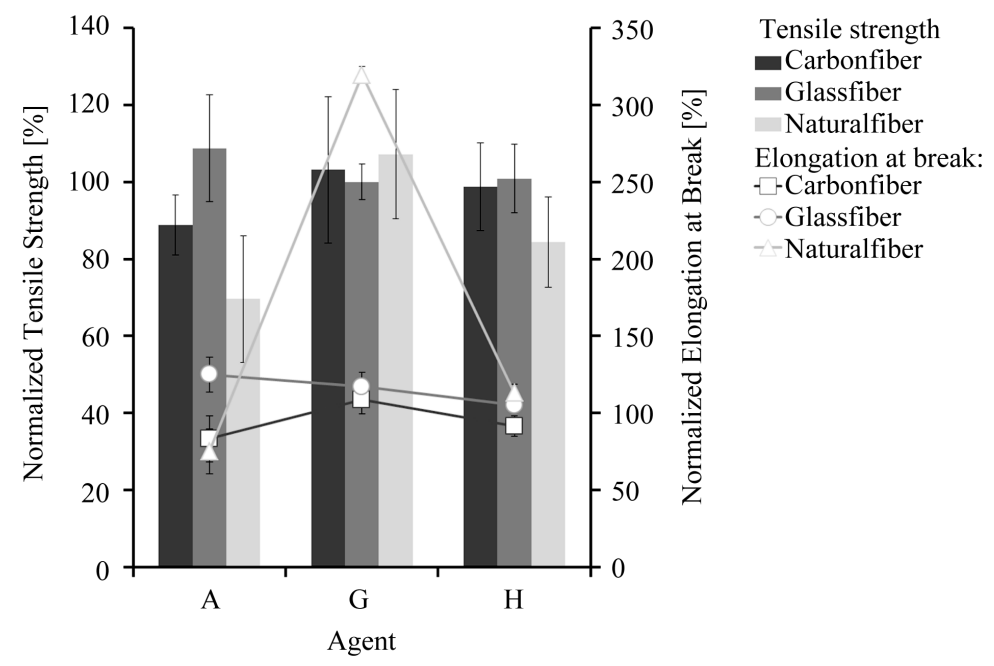

Figure 15. Influence of the agents A, G and H on carbon-, glass-, and naturalfiber. Treatment for $24 \mathrm{~h}$ is at boiling point. The columns correspond to the tensile strength values and the points to the elongation at break values after treatment; initial values are normalized to $100 \%$.

elongation at break while maintaining the tensile strength.

Concluding, it can be said about the fiber-treatment with the recycling agents, that the influence on carbon- 
and glass-fibers is relatively low. Aramid-fibers are, to some extent very labile against the chemicals, however combinations of recycling agents and decomposition regimes can be found under which the polycyanurate matrix can be dissolved without affecting the aramid-fibers.

\subsection{New Polyurethane Thermosets from Recycled Polycyanurates}

The new thermosets described in Section 3.4 exhibit glass transition temperatures of up to $128^{\circ} \mathrm{C}$, by using $14.3 \%$ of Recyclate with P-MDI as Isocyanate component (Table 3).

The HDI-containing polymers exhibit lower $\mathrm{T}_{\mathrm{g}} \mathrm{s}$. For the HDI-containing foam a $\mathrm{T}_{\mathrm{g}}$ of $75^{\circ} \mathrm{C}(13.2 \mathrm{wt}-\mathrm{\%}$ of recyclate) was found. The DMA-curves for formulations P1-P3 can be found in Figure 16.

Massive PUR-materials were obtained with the HDI-Trimer (P4 - P6), having $\mathrm{T}_{\mathrm{g}} \mathrm{s}$ ranging from $61^{\circ} \mathrm{C}$ to $80^{\circ} \mathrm{C}$. A more green version of polyurethane is formulation P3, containing besides $22.4 \mathrm{wt}-\%$ of recyclate additional $19.1 \mathrm{wt}-\%$ of castor oil as renewable component, making the resulting foam $41.5 \mathrm{wt}-\%$ green. Figure 17 shows an exemplary foam structure of formulation P1.

Massive samples were obtained by formulating water-free mixtures. An increase of $\mathrm{T}_{\mathrm{g}}$ from $66^{\circ} \mathrm{C}$ to $80^{\circ} \mathrm{C}$ was obtained (Table 3, Figure 18) by rising the amount of recyclate from $10 \mathrm{wt}-\%$ to $20 \mathrm{wt}-\%$, probably as a result of the high content of aromatic structures in the recyclate. Adding Glycerine as a crosslinker to the formulation with $20 \mathrm{wt}-\%$ of recyclate a decrease of the $\mathrm{T}_{\mathrm{g}}$ from $80^{\circ} \mathrm{C}$ to only $61^{\circ} \mathrm{C}$ was found.

Epoxide [37] and acrylate based polymers were also synthesized using the recycled polycyanurates, details will be reported in the future.

Actual research regarding additional characterization of the newly developed resins, as well as on the structure elucidation of the polycyanuratere cyclates is in progress.

\section{Conclusions and Outlook}

The authors investigate the recyclability of polycyanurate homo- and copolymers with different recycling

Table 3. Glass transition temperatures of new polyurethane formulations.

\begin{tabular}{cccccccc}
\hline Formulation & $\begin{array}{c}\mathbf{K O H}-\mathbf{v a l u e} \\
{\left[\mathbf{g} \cdot \mathbf{k g}^{-1} \mathbf{K O H}\right]}\end{array}$ & Chain extender & Isocyanate & Cross-linking agent & Blowing agent & $\begin{array}{c}\boldsymbol{\omega}_{\text {Recyclate }} \\
\text { [wt-\%] }\end{array}$ & $\boldsymbol{T}_{\mathbf{g}, \text { tan } \delta}\left[{ }^{\circ} \mathbf{C}\right.$ ] \\
\hline P1 & $486^{*}$ & 1,4-Butandiol & HDI-Biuret & Glycerin & Water & 13.2 & 75 \\
P2 & $486^{*}$ & 1,4-Butandiol & P-MDI & Glycerin & Water & 14.3 & 128 \\
P3 & $486^{*}$ & Castor oil & HDI-Biuret & Glycerin & Water & 22.4 & 94 \\
P4 & $653^{* *}$ & 1,4-Butandiol & HDI-Trimer & - & - & 10.0 & 66 \\
P5 & $653^{* *}$ & 1,4-Butandiol & HDI-Trimer & - & - & 20.0 & 80 \\
P6 & $653^{* *}$ & 1,4-Butandiol & HDI-Trimer & Glycerin & - & 20.0 & 61 \\
\hline
\end{tabular}

*Estimated hydroxyl-value; ${ }^{* *}$ Hydroxyl values determined in accordance with DIN 53240.

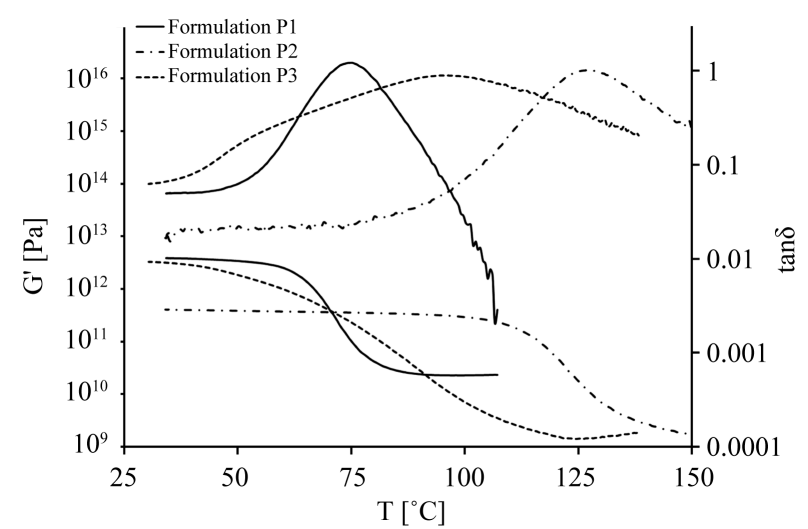

Figure 16. DMA measurements of the new PUR-foam formulations P1-P3. 


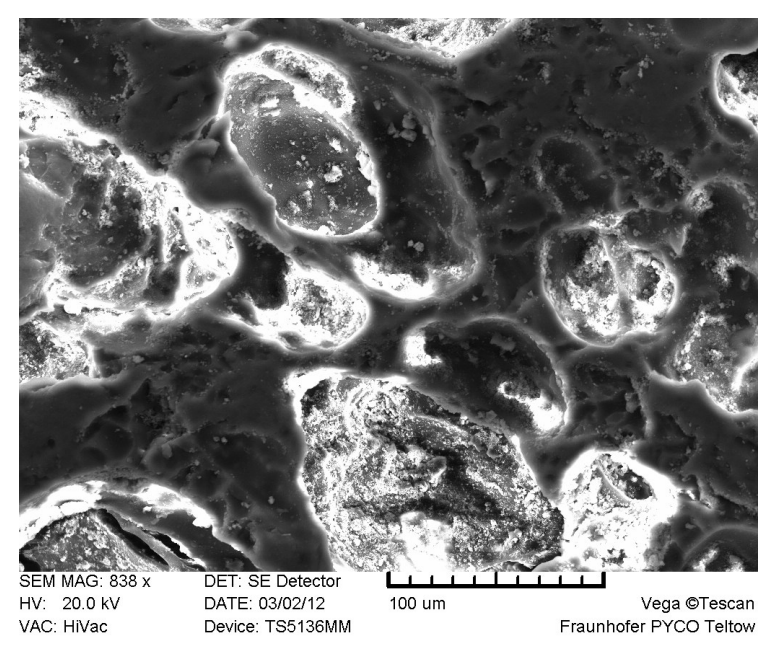

Figure 17. SEM picture of formulation $\mathrm{P} 1$, showing the foam structure (magnification $838 \times$ ).

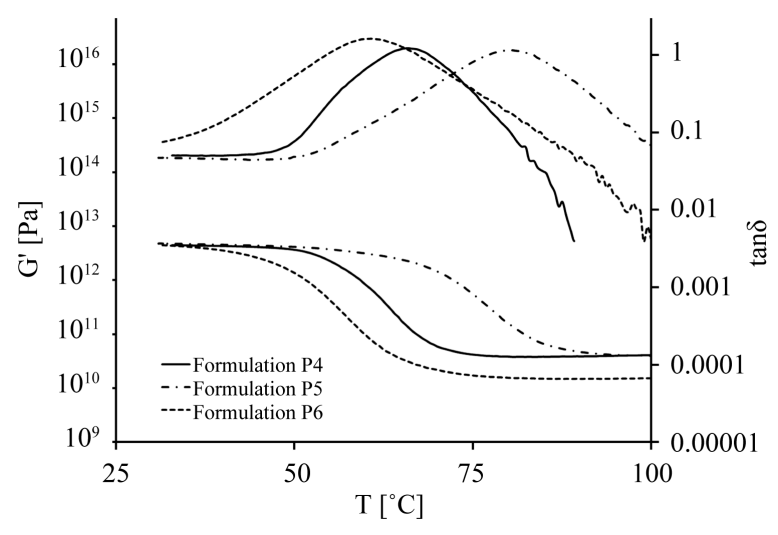

Figure 18. DMA measurements of the new massive PUR formulations P4-P6.

agents under different conditions. Also the influence of the recycling process on the most important reinforcement fibers, i.e. carbon-, glass-, aramid-, and natural-fiber is investigated. The authors find that: the recycling speed is not only dependent on the temperature, but is also significantly influenced by the particular recycling agents and the polycyanurate formulation. Hence, the stability against the recycling media can be adjusted over a broad range by adjusting the polymer composition. Furthermore, the authors find that the inorganic reinforcement fibers (carbon and glass) are almost unaffected by neither recycling agent at either temperature. Aramid-fibers degrade, depending on the particular recycling agent, from slightly up to extremely strong. This leaves one with the possibility to find a combination of matrix resin and recycling agent, which does not affect the aramid-fiber significantly. In the case of natural fibers, the dependence on the particular recycling media is very strong: some media do not affect the fiber significantly; others reduce the mechanical properties (tensile strength and elongation at break) significantly, and still others even improve both mechanical properties strongly. From the Recyclate, the authors synthesized and characterized a number of new polyurethane thermosets (foamed and solid samples) with different contents of recyclate, exhibiting $\mathrm{T}_{\mathrm{g}}$ in the range of $60^{\circ} \mathrm{C}$ to $128^{\circ} \mathrm{C}$.

Experiments on the synthesis of epoxide resins, acrylate resins and other polymer classes from the recycled polycyanuratesand experiments on the repair of polycyanurate laminates are in progress and will be reported elsewhere.

\section{Acknowledgements}

We thank Mrs. Katarina Padaszus, Mrs. Katharina Becker, Mr. Felix Herrmann, Mr. Tobias Hoffmann and Mr. 
Hadrien Schmitt, all Fraunhofer PYCO, for measurements and assistance in the lab. We also thank Dr. Juergen Schneider, Fraunhofer PYCO, and Dagmar Jones for the active support.

\section{References}

[1] Armstrong, K.B., Bevan, L.G. and Cole, II, W.F. (2005) Care and Repair of Advanced Composites. 2nd Edition, SAE International, Warrendale.

[2] Witten, E. (2014) Handbuch Faserverbundkunststoffe, Composites: Grundlagen, Verarbeitung, Anwendungen/AVKIndustrievereinigung Verstärkte Kunststoffe e.V. 4th Edition, Springer Vieweg, Wiesbaden. http://dx.doi.org/10.1007/978-3-658-02755-1

[3] Dreyer, C., Söthje, D., Klauke, K. and Bauer, M. (2013) Chemisches Recycling von Composites. MaschinenMarkt: MM Compositesworld, 118, 26-28.

[4] Drechsler, K. and Middendorf, P. (2012) New Composite Technologies for Automotive Applications. 3rd International IQPC-Congress, Wiesbaden, 3-5 December 2012, 45-56.

[5] Meilhan, N. (2013) Strategies of Global OEMs to Reduce Future Car Weight. Proceedings of the Transportation Weight Loss Diet Conference, Stuttgart, 5-6 June 2013, 40.

[6] Marsh, G. (2013) Composites Poised to Transform Airline Economics. Reinforced Plastics, 57, 18-24. http://dx.doi.org/10.1016/S0034-3617(13)70088-2

[7] Martin, D. and Bacaloglu, R. (1980) Organische Synthesen Mit Cyansäureestern. 1st Edition, Akademie-Verlag, Berlin.

[8] Martin, D. (1964) Phenyl Cyanate. Angewandte Chemie International Edition, 3, 311. http://dx.doi.org/10.1002/anie.196403112

[9] Jensen, K.A. and Holm, A. (1964) Formation of Monomeric Alkyl Cyanates by the Decomposition of 5-Alkoxy-1, 2,3,4-Thiatriazoles. Acta Chemica Scandinavica, 18, 826-828. http://dx.doi.org/10.3891/acta.chem.scand.18-0826

[10] Grigat, E. and Pütter, R. (1964) Chemie der Cyansäureester, I. Cyansäureester aus Hydroxylverbindungen und Halogencyan. Chemische Berichte, 97, 3012-3017. http://dx.doi.org/10.1002/cber.19640971107

[11] Hamerton, I. (1994) Chemistry and Technology of Cyanate Ester Resins. 1st Edition, Chapman \& Hall, Glasgow. http://dx.doi.org/10.1007/978-94-011-1326-7

[12] Productflyer (2009) LONZA Primaset Cyanate Esters: The Next Generation of High Performance Thermosets. Switzerland.

http://www.lonza.com/products-services/materials-science/high-performance-materials/primaset-cyanate-esters.aspx

[13] Bauer, M., Decker, D., Richter, F. and Gwiazda, M. (2010) Hybrid Polymers Made of Cyanates and Silazanes, Method for the Production and Use Thereof. Patent EP Patent 2408846 B1.

[14] Dreyer, C., Schneider, J., Göcks, K., Beuster, B., Bauer, M., Keil, N., Yao, H., Zawadzki, C. and Radmer, O. (2002) Polymere für Anwendungen in der integrierten Optik-Ein Überblick mit ausgewählten Beispielen. e \& i Elektrotechnik und Informationstechnik, 120, 178-185.

[15] Dreyer, C.J., Bauer, M., Bauer, J., Keil, N., Yao, H.H. and Zawadzki, C. (2001) Polycyanurate Ester Resins with Low Loss and Low Birefringence for Use in Integrated Optics. Linear and Nonlinear Optics of Organic Materials, 4461, 188-199. http://dx.doi.org/10.1117/12.449847

[16] Dreyer, C., Bauer, M., Bauer, J., Keil, N., Yao, H.H. and Zawadzki, C. (2002) Reduction of the Optical Loss and Optimization of Polycyanurate Thermosets Used in Integrated Optics. Microsystem Technologies, 7, 229-238, http://dx.doi.org/10.1007/s005420100102

[17] Söthje, D., Dreyer, C., Bauer, M., Schulze, C., Riedel, U. and Eppinger, A. (2013) Mikrowellenhärtbareduromere Matrixharze für Automobilanwendungen: Entwicklung Reparatur- und Recyclingfähiger Leichtbaumaterialien. Konstruktion, 65, IW 5-7.

[18] ACARE (2013) Roadmap for Cross-Modal Transport Infrastructure Innovation. http://www.acare4europe.org/sites/acare4europe.org/files/document/ETP\%20Roadmap.pdf

[19] Directive 2000/53/EC of the European parliament and of the Council (2000) End-of Life Vehicles.

[20] Xiao, X., Hoa, S.V. and Street, K.N. (1994) Repair of Thermoplastic Resin Composites by Fusion Bonding. In: Damico, D.J., Wilkinson, Jr., T.L. and Niks, L.F.S., Eds., Composites Bonding, 1227, 30-44.

[21] Davies, P., Cantwell, W.J., Jar, P.Y., Bourban, P.E., Zysman, V. and Kausch, H.H. (1991) Joining and Repair of Carbon Fiber-Reinforced Thermoplastics. Composites, 22, 425-431. http://dx.doi.org/10.1016/0010-4361(91)90199-Q

[22] Varadan, V.K. and Varadan, V.V. (1991) Microwave Joining and Repair of Composite Materials. Polymer Engineer- 
ing \& Science, 31, 470-486. http://dx.doi.org/10.1002/pen.760310703

[23] Dang, W., Kubouchi, M., Sembokuya, H. and Tsuda, K. (2005) Chemical Recycling of Glass Fiber Reinforced Epoxy Resin Cured with Amine Using Nitric Acid. Polymer, 46, 1905-1912. http://dx.doi.org/10.1016/j.polymer.2004.12.035

[24] Liang, B., Pastine, S.J. and Qin, B. (2012) Novel Agents for Reworkable Epoxy Resins. WO Patent 2012/071896 A1.

[25] Williams, P., et al. (2003) Recycling of Automotive Composites-The Pyrolysis Process and its Advantages. Materials World, 11, 24-26.

[26] Holl, R. (1982) Process to Increase the Yield of Pyrolysis Oil and to Shorten the Duration of the Pyrolysis. Patent GB 2129009 A.

[27] Giehr, A., Höver, H., Keim, K., Joachim K. and Neuwirth, O. (1984) Verfahren zur Aufarbeitung von Kohlenstoff enthaltenden Abfällen. Patent DE 3442506 C2.

[28] Tippmer, K. (1994) Verfahren zur thermischen Spaltung von Abfall-Kunststoff-Gemischen. Patent DE 4412941 A1.

[29] Bräutigam, K.R., Kupsch, C., Reßler, B. and Sardemann, G. (2003) Analyse der Umweltauswirkungen bei der Herstellung, dem Einsatz und der Entsorgung von CFK-bzw. Aluminiumrumpfkomponenten. Research Report FZKA 6879, Forschungszentrum Karlsruhe, Karlsruhe.

[30] Braun, D., Gentzkow, W. and Rudolf, A. (1998) Recycling von Duroplastwerkstoffen. Patent DE 19839083.

[31] Zia, K.M., Bhatti, N.H. and Bhatti, I.A. (2007) Methods for Polyurethane and Polyurethane Composites, Recycling and Recovery: A Review. Reactive and Functional Polymers, 67, 675-692. http://dx.doi.org/10.1016/j.reactfunctpolym.2007.05.004

[32] Kaeufer, H. and Bollin, H. S. (1996) Verfahren für das Recycling von Epoxidharz enthaltenden Erzeugnissen. Patent WO001996016112A1.

[33] (2013) http://www.connoratech.com/technology/recyclable-epoxy-data/

[34] El Gersifi, K. Durand, G. and Tersac, G. (2006) Solvolysis of Bisphenol A Diglycidyl Ether/Anhydride Model Networks. Polymer Degradation and Stability, 91, 690-702. http://dx.doi.org/10.1016/j.polymdegradstab.2005.05.021

[35] Bauer, J., Bauer, M. and Göcks, K. (1997) Method of Decomposing Polycyanurate-Containing Materials. US Patent No: 000005691388A.

[36] Dreyer, C. Söthje, D. and Bauer, M. (2013) Progress in Recyclable Cyanate Resins. Thermosets 2013 from Monomers to Components Proceedings of the 3rd International Conference on Thermosets, Berlin, 18-20 September 2013, 159-162.

[37] Söthje, D. Dreyer, C. and Bauer, M. (2013) Advanced Possibilities in Thermoset Recycling. Thermosets 2013 from Monomers to Components Proceedings of the 3rd International Conference on Thermosets, Berlin, 18-20 September 2013, 219-223.

[38] (2013) Determination of Hydroxyl Value. German Industry Standard, DIN 53240. 